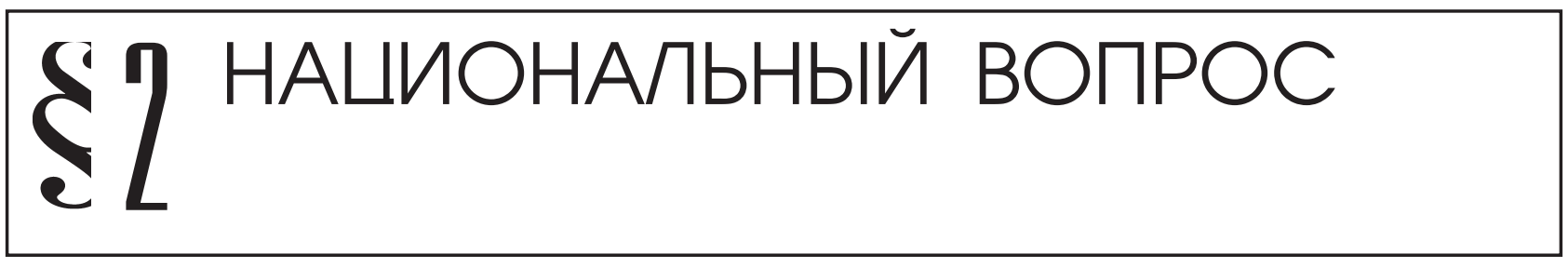

Музакаев Д.А.

\title{
ЕВРОПЕИЗАЦИЯ ЧЕЧЕНСКОЙ КУЛЬТУРЫ КАК ЧАСТЬ ПРОЦЕССА МОДЕРНИЗАЦИИ ЧЕЧЕНСКОГО ОБЩЕСТВА В 60-80-е гГ. ХХ ВЕКА
}

\begin{abstract}
Аннотация: Анализ этнополитических прочессов в Чеченской Республике позволяет выделить несколько этапов в развитии чеченской культуры, связанных с различными социально-политическими условиями, борьбой чеченского народа за свою независимость, отстаиванием национальной культуры и самобытности, становлением Чеченской Республики в качестве государственного образования в составе Российской Федерации. В данной статье автор анализирует влияние прочесса модернизации чеченского общества в 60-80-е г2. ХХ века на развитие национальной культуры, которое протекало в русле сближения с общеевропейской культурой. Вектор этого развития был направлен на интеграцию чеченского народа в общероссийское соииокультурное пространство. Сущностное содержание этой трансформации состояло в переменах, обеспечивавших институчиональные, кадровые и содержательные основы разнообразного и богатого культурного производства на основах светской и европейской традиции, в рамках которой развивалась вся советская культура. Для раскрытия темы статьи автор использовались политологические методы и подходы: метод терминологического анализа, для выявления сущности таких понятий как "традиционная этническая культура", "национальная политика", "этнокультурный процесс", "этническая самоидентификация", "европеизация". Для определения места и роли традиционной этнической культуры в жизни чеченского общества, а так же ее европеизачии, автор использовал метод теоретического анализа. Автор приходит к выводу о том, что постепенное размыввание чеченской традиционной культуры открывало дорогу не только к широким культурным заимствованиям, но и внешнему влиянию, которое отражалось на всех сторонах жизни чеченского общества, в том числе и в политической сфере. Опыт Чеченской Республики свидетельствует, что высокая востребованность национальной культуры положительно влияет на внутреннюю консолидаџию этнического сообщества и придает дополнительную устойчивость его духовной, сочиальной и политической жизни.
\end{abstract}

Review: Analysis of ethnic political processes in the Chechen republic allows to single out several stages in the development of the Chechen culture regarding various social and political conditions, the fight of the Chechen people for independence, protection of national culture and identity, formation of the Chechen Republic as a public formation within the Russian Federation. In this article the author analyzes the influence of the process of modernization of the Chechen society in 1960s - 1980s upon the development of national culture, which was coming closer to the general European culture. The vector of this development was aimed at the integration of the Chechen people into the general Russian social and cultural space. The contents of this transformation involved the changes guaranteeing institutional, cadres and content-based fundamentals of varied and rich cultural production based upon secular European tradition, which was the basis for the entire Soviet culture. In order to discuss this issue the author employed political science methods and approaches: the method of terminological analysis in order to reveal the nature of the terms, such as "traditional ethnic culture", "national policy", "ethnic cultural process", "ethnic identity", "Europeanization". In order to reveal place and role of traditional ethnical culture in the life of the Chechen community and its Europeanization, the author used the method of theoretical analysis. The author draws a conclusion that step-by-step erosion of the Chechen culture cleared the path for wide range of cultural borrowing and external influences, which were reflected in all of the spheres of life of the Chechen community, including its politi- 
cal sphere. The experience of the Chechen republic shows that high demand for the national culture has a positive influence upon the internal consolidation of the ethnical community, bringing additional sustainability to its spiritual, social and political life.

Ключевые слова: Европеизачия чеченской культуры, модернизачия чеченского общества, трансформаичя, традищия, общество, государство, сочиокультурное пространство, начиональная политика, межнаииональные отночения, национальная культура.

Keywords: Europeanization of the Chechen culture, modernization of the Chechen community, transformation, tradition, society, state, social-cultural area, national policy, international relations, national culture.

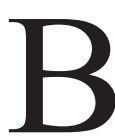
60-80-х гг. ХХ в. произошла довольно быстрая (буквально на протяжении одного поколения) модернизация чеченского общества, которая сопровождалась формированием и распространением новых поведенческих стереотипов. Вместе с тем, в условиях, сложившихся в Чечено-Ингушской АССР, модернизация чеченского общества носила весьма противоречивый характер, а развитие чеченской культуры шло в направлении европеизации, когда обществом усваивались общечеловеческие ценности. Нельзя также сбрасывать со счетов то обстоятельство, что за годы депортации (1944-1956 гг.) социально-профессиональная структура чеченского общества претерпела значительные изменения, произошло заметное размывание границ между различными социальными стратами, что отражалось, в частности, на культурных предпочтениях чеченского общества.

Кроме того, депортация отрицательно сказалась на образовательном уровне чеченского общества. В отличие от соседних республик в восстановленной Чечено-Ингушской АССР пришлось вновь решать проблему ликвидации неграмотности взрослого населения - по данным за 1959 года более $10 \%$ взрослых жителей республики не умели ни читать, ни писать ${ }^{1}$.

С массовым возвращением чеченцев и ингушей из ссылки власти Чечено-Ингушетии столкнулись также с элементарной нехваткой общеобразовательных школ, прежде всего в сельской местности. А поскольку для коренного населения республики на протяжении $60-80$-х годов был характерен высокий уровень рождаемости, то проблема строительства новых школ оставалась актуальной довольно длительное время. Кроме того, в общеобразовательных учреждениях постоянно не хватало

\footnotetext{
${ }^{1}$ Репрессированные народы России: чеченцы и ингуши: Документы, факты, комментарии. - М., 1994. - С. 235.
}

учителей (прежде всего национальных кадров), особенно в сельской местности, что отрицательно сказывалось на уровне учебного процесса.

Наконец, еще одной серьезной проблемой стала утрата школьными учреждениями национального характера. Если до депортации начальная школа для чеченских детей существовала на родном языке, то теперь с первого и до десятого класса обучение велось на русском языке. Чеченский язык и чеченская литература изучались наравне с иностранными языками и только в чеченских селениях (в городских школах чеченские дети родной языки и родную литературу не изучали вообще).

Первое время ликвидацию национальной школы республиканские власти объясняли отсутствием достаточного количества национальных учителей. Так, в 1958 г. из 8 тысяч педагогов только 1440 были чеченцами и ингушами, причем из последних только 190 человек имели высшее образование ${ }^{2}$. Специально для того, чтобы активизировать подготовку учителей родного языка и литературы при Чечено-Ингушском педагогическом институте (будущий университет) было открыто отделение чечено-ингушской филологии. Однако, вскоре стало очевидным, что на деле руководители Чечено-Ингушской АССР вовсе не стремились сделать чеченскую школу национальной, утверждая, что благодаря преподаванию на русском языке с первого года обучения, дети хорошо знают русский язык и впоследствии легче усваивают программу старших классов.

На самом же деле в мононациональных чеченских селениях (а их было подавляющее большинство) учителям первых классов приходилось затра-

\footnotetext{
${ }^{2}$ Овхадов М. Об образовательном уровне чеченцев (на основе материалов переписей 1959-1989 гг.) // Вестник ЛАМ.
} 2001. № 7 (11). - C. 91. 


\section{Политика и общество 7 (115) • 2014}

чивать колоссальные усилия, чтобы научить детей русскому языку. В результате, школьная программа плохо усваивалась. Чтобы как-то решить эту проблему, в начале 80-х гг. началось введение подготовительного класса для 6-летних детей. За один учебный год дети не только пополняли свой запас русских слов, но и изучали основы грамматики чеченского языка. Однако после введения 11-летнего обучения школы Чечено-Ингушетии были вынуждены отказаться от подготовительного класса и ситуация с национальной школой вновь зашла в тупик. При этом явную дискриминацию чеченского языка руководство республики преподносило, как важное достижение «национальной политики советского государства».

К идее воссоздания национальной школы власти Чечено-Ингушетии вернулись в 1990 г., когда преподавание всех предметов по программе начальной школы должно было вестись на родном языке. Была разработана довольно амбициозная программа, в соответствии с которой на чеченский язык обучения должна была перейти 421 школа ${ }^{3}$, однако ее практическая реализация так и не началась.

Между тем, отсутствие национальной школы рикошетом било по национальной культуре, поскольку дети, попав в школу, оказывались в непривычной языковой и культурной среде. Это порождало не только трудности в усвоении учебной программы, но и девальвировало в глазах детей ценности традиционной национальной культуры. Таким образом, отсутствие национальной школы стало одним из многих факторов, способствовавших дальнейшей культурной маргинализации чеченского общества.

В целом система школьного образования в Чечено-Ингушетии была построена таким образом, что представители коренных народов оказывались в более невыгодных условиях в плане получения высшего образования - выпускникам сельских школ было гораздо труднее поступить в вузы. Например, в 1957 году из каждых 10 тысяч чеченцев только 19,1 имели высшее и среднее специальное образование, в то время как в среднем по стране этот показатель составлял 326,3. Даже по сравнению с другими репрессированными народами Северного Кавказа чеченцы находи-

${ }^{3}$ Мовтаев С. Долгожданный поиск // Грозненский рабочий. 1990. 20 июля. - С. 3. лись в худших условиях - их средний образовательный уровень был в 4 раза ниже ${ }^{4}$.

Тем не менее, партийное руководство Чечено-Ингушетии отказалось предоставлять чеченцам и ингушам гарантированное количество мест в вузах республики, а при направлении на учебу в вузы других республик и областей национальный фактор во внимание не принимался. Поэтому в 70-х годах на каждую тысячу чеченцев в республиканских вузах обучалось всего 4,5 человек, в то время как представителей русскоязычных наций - 18-205. В 1981 году чеченцы составляли уже около половины населения Чечено-Ингушетии, но среди студентов республиканских вузов их было чуть менее $32 \%$. В то же время русские (менее 40\% населения) составляли половину студентов $^{6}$. Даже в конце 80 -х годов на 10 тысяч чеченцев приходилось 142 студента, в то время как в среднем по России $-190^{7}$.

Постепенно разрыв в образовательном уровне между чеченцами и соседними народами все же сокращался. Так, за период с 1959 по 1970 год число лиц с высшим и средним образованием среди русских жителей Чечено-Ингушетии увеличилось в 2,3 раза, среди ингушей - в 4,9 раза, а среди чеченцев - в 7,3 раза. Если в 1959 году среди 100 чеченцев старше 10 лет только 1 имел высшее образование, то в 1979 году их было уже $18^{8}$. К 1989 г. удельный вес чеченцев, имеющих высшее образование, увеличился в 37 раз и, тем не менее, преодолеть полностью отставание от большинства других народов Советского Союза не удалось ${ }^{9}$.

${ }^{4}$ Овхадов М. Об образовательном уровне чеченцев (на основе материалов переписей 1959-1989 гг.) // Вестник ЛАМ. 2001. № 7 (11). - C. 11.

5 Жизнь, отданная науке // Ойла («Мысль»). 1998. № 1. - С. 91. ${ }^{6} 60$ лет Чечено-Ингушской АССР: Статистический сборник. - Грозный, 1982. - С. 102.

7 Овхадов М. Об образовательном уровне чеченцев (на основе материалов переписей 1959-1989 гг.) // Вестник ЛАМ. 2001. № 7 (11). - С. 12.

8 Заурбекова Г.В. Основные тенденции изменения социально-классового состава населения Чечено-Ингушской АССР за годы Советской власти // Этносоциальные и культурнобытовые процессы в Чечено-Ингушетии. - Грозный, 1986. - C. 27, 29.

9 Овхадов М. Об образовательном уровне чеченцев (на основе материалов переписей 1959-1989 гг.) // Вестник ЛАМ. 2001. № 7 (11). - C. 12. 
В целом же, период 60 - 80-х годов стал временем довольно быстрой (хотя и противоречивой) модернизации чеченского общества, которая сопровождалась формированием и распространением новых поведенческих стереотипов.

Вместе с тем, целый ряд факторов (непростое материальное положение большинства семей, предельно сжатые сроки модернизации и др.) способствовали сохранению широких семейно-родственных связей. Причем теперь родственным связям по линии жены в семьях придается не меньшее значение, чем по линии формального главы семьи. Со своей стороны сохраняющаяся прочность семейнородственных связей способствовала тому, что они играли важную роль и во всех сферах общественной и политической жизни чеченского общества.

Полное пренебрежение партийного руководства Чечено-Ингушетии к развитию чеченского языка негативно влияло на развитие всей чеченской национальной культуры. Так, по сравнению с периодом 20 - 30-х годов заметно сузился репертуар национального книгоиздания. На чеченском языке практически перестала издаваться научно-популярная литература, сократилось количество переводов произведений художественной литературы на чеченский язык. При этом значительные средства затрачивались на перевод и издание на чеченском языке разного рода партийной литературы, не пользовавшейся спросом у чеченского читателя и никак не способствовавшей развитию чеченского литературного языка.

Однако несмотря ни на что чеченская национальная культура и искусство продолжали развиваться. Развивались благодаря усилиям деятелей культуры и искусства, которые как будто пытались наверстать все, что было упущено за годы депортации.

В целом 60 - 80-е годы стали периодом не только быстрого развития чеченского профессионального искусства, но и дальнейшей европеизации всей чеченской национальной культуры. Несмотря на то, что основная масса чеченцев не принимала коммунистическую идеологию со свойственным ей атеистическим взглядом на мир - ценности европейской культуры (в ее русском варианте) получали все более широкое распространение в чеченском обществе. Значительную роль в этом играли учреждения культуры - клубы, дома культуры, библиотеки. Именно в период 60-80-х гг. произошло близкое знакомство широких слоев чеченского общества с европейской культурой (в ее русско-советском варианте) и усвоение ее основных духовных ценностей на бытовом уровне. Это оказало влияние на весь образ жизни чеченского народа и отразилось буквально во всем: подавляющее большинство чеченцев свободно говорило по-русски и носило европейскую одежду, они были знакомы с произведениями русской и мировой литературы, любили и знали кино, театр и т.д. Русский язык для многих становится вторым родным языком, а уже в середине 70-х до 50\% чеченцев пользуются им даже на внутрисемейном уровне ${ }^{10}$.

Таким образом, за период с конца 50-х до начала 90-х годов ХХ века происходило быстрое развитие чеченской национальной культуры и искусства, что стало частью более широкого процесса модернизации чеченского общества. Как отмечают современные российские и чеченские исследователи, вектор этого развития в целом был направлен на интеграцию чеченского народа в общероссийское социокультурное пространство. Сущностное содержание этой трансформации состояло в переменах, обеспечивавших институциональные, кадровые и содержательные основы разнообразного и богатого культурного производства на основах светской и европейской традиции, в рамках которой развивалась вся советская культура ${ }^{11}$.

\section{Библиография:}

1. Репрессированные народы России: чеченцы и ингуши: Документы, факты, комментарии. М., 1994.

2. Овхадов М. Об образовательном уровне чеченцев (на основе материалов переписей 19591989 гг.) // Вестник ЛАМ. 2001. № 7 (11).

3. Мовтаев С. Долгожданный поиск // Грозненский рабочий. 1990. 20 июля.

4. Жизнь, отданная науке // Ойла («Мысль»). 1998. № 1.

5. 60 лет Чечено-Ингушской АССР: Статистический сборник. - Грозный, 1982.

\footnotetext{
${ }^{10}$ Дулерайн Р.П. О взаимосвязи национального и интернационального в коммунистическом воспитании // Социология, атеизм, религия. Т. 3. Вып. 1. - Грозный, 1976. - С. 177.

${ }^{11}$ Тишков В.A. Война и культура // Культура Чечни: история и современные проблемы. - М., 2002. - С. 11-12.
} 


\section{Политика и общество 7 (115) • 2014}

6. Заурбекова Г.В. Основные тенденции изменения социально-классового состава населения Чечено-Ингушской АССР за годы Советской власти // Этносоциальные и культурно-бытовые процессы в Чечено-Ингушетии. - Грозный, 1986.

7. Дулерайн Р.П. О взаимосвязи национального и интернационального в коммунистическом воспитании // Социология, атеизм, peлигия. Т. 3. Вып. 1. - Грозный, 1976.

8. Тишков В.А. Война и культура // Культура Чечни: история и современные проблемы. - М., 2002.

9. Грудцына Л.Ю., Петров С.М. Власть и гражданское общество в России: взаимодействие и противо- стояние // Административное и муниципальное право. - 2012. - 1. - C. $19-29$.

10. М.Б. Напсо, М.Д. Напсо Права народов и права индивида: социально-философские и правовые аспекты соотношения индивидуальных и коллективных прав // Право и политика. - 2012. - 11. - С. 1907 - 1917.

11. Иванько Н.А., Торукало В.П. Модель государственного управления в социальной сфере жизни современного российского общества // Политика и Общество. - 2013. - 7. - C. 806 - 816. DOI: 10.7256/18128696.2013.7.7439.

12. Жаровская И.М. Социальная культура народа и концепт государственной власти: проблемы соотношения // Право и политика. - 2013. - 7. - C. 915 - 918. DOI: 10.7256/1811-9018.2013.7.7246.

13. О. А. Семченко Международный форум «Традиционная культура как стратегический ресурс устойчивого развития общества» (17-20 апреля 2012 года; Могилев, Республика Беларусь) // Культура и искусство. - 2012. - 4. - С. $109-110$.

14. Щупленков О.В., Щупленков Н.О. Трансформация власти в процессе построения гражданского общества в России // NB: Проблемы общества и политики. - 2013. - 9. - С. 20 - 88. DOI: 10.7256/2306-0158.2013.9.9053. URL: http://www.e-notabene.ru/pr/article_9053.html

\section{References (transliteration):}

1. Ovkhadov M. Ob obrazovatel'nom urovne chechentsev (na osnove materialov perepisei 1959-1989 gg.) // Vestnik LAM. 2001. № 7 (11).

2. Movtaev S. Dolgozhdannyi poisk // Groznenskii rabochii. 1990. 20 iyulya.

3. Zaurbekova G.V. Osnovnye tendentsii izmeneniya sotsial'no-klassovogo sostava naseleniya Checheno-Ingushskoi ASSR za gody Sovetskoi vlasti // Etnosotsial'nye i kul'turno-bytovye protsessy v Checheno-Ingushetii. - Groznyi, 1986.

4. Dulerain R.P. O vzaimosvyazi natsional'nogo i internatsional'nogo v kommunisticheskom vospitanii // Sotsiologiya, ateizm, religiya. T. 3. Vyp. 1. - Groznyi, 1976.

5. Tishkov V.A. Voina i kul'tura // Kul'tura Chechni: istoriya i sovremennye problemy. - M., 2002.

6. Grudtsyna L.Yu., Petrov S.M. Vlast' i grazhdanskoe obshchestvo v Rossii: vzaimodeistvie i protivo- stoyanie // Administrativnoe i munitsipal'noe pravo. - 2012. - 1. - C. $19-29$.

7. M.B. Napso, M.D. Napso Prava narodov i prava individa: sotsial'no-filosofskie i pravovye aspekty sootnosheniya individual'nykh i kollektivnykh prav // Pravo i politika. - 2012. - 11. - C. 1907 - 1917.

8. Ivan'ko N.A., Torukalo V.P. Model' gosudarstvennogo upravleniya $\mathrm{V}$ sotsial'noi sfere zhizni sovremennogo rossiiskogo obshchestva // Politika i Obshchestvo. - 2013. - 7. - C. 806 - 816. DOI: 10.7256/1812-8696.2013.7.7439.

9. Zharovskaya I.M. Sotsial'naya kul'tura naroda i kontsept gosudarstvennoi vlasti: problemy sootnosheniya // Pravo i politika. - 2013. - 7. - C. 915 -918. DOI: 10.7256/1811-9018.2013.7.7246.

10. O. A. Semchenko Mezhdunarodnyi forum «Traditsionnaya kul'tura kak strategicheskii resurs ustoichivogo razvitiya obshchestva» (17-20 aprelya 2012 goda; Mogilev, Respublika Belarus') // Kul'tura i iskusstvo. - 2012. - 4. - C. $109-110$.

11. Shchuplenkov O.V., Shchuplenkov N.O. Transformatsiya vlasti $\mathrm{v}$ protsesse postroeniya grazhdanskogo obshchestva v Rossii // NB: Problemy obshchestva i politiki. - 2013. - 9. - C. 20-88. DOI: 10.7256/2306-0158.2013.9.9053. URL: http:// www.e-notabene.ru/pr/article_9053.html 